\title{
Publisher Correction: The Eastring gas pipeline in the context of the Central and Eastern European gas supply challenge
}

Matúš Mišík and Andrej Nosko

Correction to: Nature Energy https://doi.org/10.1038/s41560-017-0019-6 (2017); published online 30 October 2017.

In the version of this Perspective originally published, the accepted date was incorrectly given as 15 October 2017; it should have read 15 September 2017. This has now been corrected in all versions of the Perspective. 